\title{
A CLÍNICA FONOAUDIOLÓGICA E A LINGUAGEM ESCRITA: ESTUDO DE CASO
}

\author{
Speech therapy clinic and the written language: case study
}

\author{
Ana Cristina Guarinello (1), Giselle Massi ${ }^{(2)}$, Ana Paula Berberian ${ }^{(3)}$, Keylla Dariele Rivabem ${ }^{(4)}$
}

\section{RESUMO}

Objetivo: partindo do pressuposto que a atividade lingüística é constitutiva do sujeito, esse trabalho busca discutir o processo de apropriação da escrita, na clínica de linguagem, a partir da relação que o aprendiz estabelece com o outro, fonoaudiólogo. Métodos: foi analisado longitudinalmente o caso de um sujeito dito portador de distúrbio de leitura e escrita, o qual antes de submeter-se a avaliação fonoaudiológica apresentava produções escritas distantes da convenção ortográfica. Resultados: a terapia de linguagem foi eficiente para apropriação da modalidade escrita, já que no decorrer do tratamento houve melhora e superação das queixas. Conclusão: por meio da atividade conjunta de construção da escrita, na clínica de linguagem, entre o sujeito dessa pesquisa e o fonoaudiólogo, o primeiro pode ser percebido como alguém capaz de fazer uso significativo da escrita.

DESCRITORES: Linguagem; Escrita Manual; Fonoterapia

\section{INTRODUÇÃO}

O presente trabalho teve sua origem a partir da constatação de um aumento significativo de encaminhamentos para avaliações e atendimentos de crianças consideradas como portadoras de dificuldade ou distúrbio de aprendizagem de leitura e escrita à clínica fonoaudiológica ${ }^{1,2}$.

Esses encaminhamentos, em geral, são fundamentados no fato destas crianças não seguirem o padrão de aprendizagem estabelecido pela escola para essa modalidade de linguagem. Na prática clínica, observa-se também que os profissionais envolvidos no diagnóstico e no tratamento destas crianças - médicos, psicólogos, fonoaudiólogos e

(1) Fonoaudióloga; Docente do Programa de Mestrado e Doutorado em Distúrbios da Comunicação da Universidade Tuiuti do Paraná; Doutora em Estudos Lingüísticos pela Universidade Federal do Paraná.

(2) Fonoaudióloga; Docente do Programa de Mestrado e Doutorado em Distúrbios da Comunicação da Universidade Tuiuti do Paraná; Doutora em Estudos Lingüísticos pela Universidade Federal do Paraná.

(3) Fonoaudióloga; Vice-Coordenadora do Programa de Mestrado e Doutorado em Distúrbios da Comunicação da Universidade Tuiuti do Paraná; Doutora em História pela Pontifícia Universidade Católica de São Paulo.

(4) Fonoaudióloga Clínica; Mestre em Distúrbios da Comunicação pela Universidade Tuiuti do Paraná. psicopedagogos - em muitos casos confirmam a suspeita da escola, na medida em que se afastam de critérios lingüísticos capazes de esclarecer o processo de apropriação do objeto escrito ${ }^{1,2}$.

Ressalta-se, porém, que não é possível falar sobre dificuldades de leitura e escrita de modo consensual, pois há discordâncias de caráter etiológico, sintomatológico e terminológico acerca dessa temática ${ }^{3}$.

Estudiosos da educação alinhados à visão neuropsicológica 4-6 apontam sintomas como dificuldades para discriminar formas, tamanhos e cores; dificuldades na discriminação de figura-fundo; problemas de noção corporal; dificuldades na coordenação de movimentos. Citam ainda disfunção cerebral relacionada ao sistema nervoso central e ao "amadurecimento" desse sistema ${ }^{7}$. Nessa direção, a área educacional, assim como a médica, apresenta uma tendência em detectar falhas orgânicas, localizando os problemas no aprendiz ${ }^{3,8,9}$. Entretanto, algumas pesquisas discutem criticamente essas posições e questionam: "de onde vem a força do pressuposto de que problemas de linguagem são determinados por dificuldades perceptuais, mesmo frente aos sucessivos fracassos em se estabelecer objetiva e claramente as relações entre percepção e linguagem?" 10.

$\mathrm{Na}$ escola, de forma geral, questões educacionais, culturais e familiares não são devidamente 
consideradas no processo de construção da escrita, assim como não são priorizadas as funções, usos e valores dessa modalidade de linguagem. Desconsidera-se que, nesse processo, a criança pode errar, formular hipóteses, questionar e manipular a escrita, como faz no processo de constituição da oralidade, e geralmente são ressaltados aspectos gráficos, em detrimento de aspectos textuais ${ }^{11,12}$.

Com efeito, grande parte dos pacientes encaminhados para a clínica fonoaudiológica apresenta diagnósticos de falhas cognitivas, motoras, perceptuais, como por exemplo, alteração no processamento auditivo central ${ }^{13}$. Contudo, na clínica da linguagem, quando são realizadas a entrevista inicial e a avaliação, percebe-se que a queixa maior da criança e de seus pais relaciona-se com dificuldades vinculadas à linguagem escrita e não a dificuldades de percepção auditiva ou visual. Além disso, observa-se que as inadequações ortográficas, que tanto preocupam professores e pais, ao invés de serem consideradas, conforme uma perspectiva constitutiva de linguagem, como parte do processo de aquisição da escrita ${ }^{11}$, são em geral avaliadas equivocadamente como sinais patológicos e, geralmente, as condições sociais de domínio da leitura e escrita vivenciadas de forma diversa e desigual pela população brasileira são desconsideradas ${ }^{12,14}$.

Contrariando uma visão que toma a linguagem por um viés organicista, estudos lingüísticos relacionam a escrita com seu uso efetivo, considerando as condições de produção da linguagem e a relação estabelecida entre autor e leitor ${ }^{15-17}$. Estudos pautados na ótica discursiva e interacionista da linguagem trazem novas possibilidades de compreensão do processo de apropriação da escrita ${ }^{18}$.

A reflexão teórica que embasa este estudo afasta-se de perspectivas que não consideram a historicidade da linguagem, as situações efetivas de uso da escrita e o contexto social das interações verbais. Antes disso, toma a linguagem como trabaIho social e histórico e considera o texto na perspectiva do diálogo, para concretização da prática interpessoal em situações de uso efetivo, envolvendo o eu e o outro ${ }^{18-21}$.

Nessa direção, esta pesquisa tem como objetivo discutir o processo de apropriação da escrita, na clínica de linguagem, a partir da interação que o aprendiz estabelece com o outro, terapeuta/fonoaudiólogo.

\section{MÉTODOS}

A pesquisa em questão foi realizada na Clínica de Fonoaudiologia da Universidade Tuiuti do Paraná, tomando como objeto o caso clínico de um sujeito adolescente que freqüentou terapia fonoau- diológica durante o ano de 2005. Para análise longitudinal do caso, foram utilizadas as informações contidas no prontuário do paciente, que constam de entrevista inicial, avaliação, relatórios bimestrais, relatórios de visitas à escola, registros diários de terapia e exames complementares, como laudos médicos e educacionais. Esse paciente foi atendido por uma estagiária do curso de Fonoaudiologia da mesma Universidade, com orientação do supervisor responsável que se colocaram à disposição para o esclarecimento de qualquer dúvida. Cabe notificar que a utilização dos dados foi autorizada pela estagiária, pelo supervisor e pela família do paciente.

O sujeito da pesquisa, reconhecido pela inicial $A$, é um menino nascido em 20/03/1992, encaminhado em 18/11/2004, para tratamento fonoaudiológico pelo neuropediatra com o laudo de desatento e disléxico.

Com relação ao trabalho realizado na Clínica de Fonoaudiologia da Universidade Tuiuti do Paraná (UTP), esse se fundamenta a partir de uma perspectiva constitutiva de linguagem ${ }^{22} \mathrm{e}$, portanto, os procedimentos terapêuticos enfatizam o uso social da linguagem por meio de atividades significativas e contextualizadas.

O processo clínico fonoaudiológico se desenvolveu durante oito meses, uma vez por semana, em sessões de 40 minutos, de março a outubro de 2005. No processo de avaliação (março 2005) e durante todo o processo terapêutico, foram utilizados procedimentos terapêuticos baseados em duas estratégias: 1) o terapeuta promovia ao sujeito acesso e leitura de materiais escritos ou visuais (seqüências de figuras, fotos, histórias, jornais, livros, filme em vídeo). Após essa etapa o terapeuta, solicitava ao sujeito a elaboração de um texto a partir de tal material; 2) a partir do diálogo de temas de interesse comum estabelecidos entre o terapeuta e o sujeito, esse último elaborava textos registrando aspectos mais relevantes (ex.: atividades preferidas, filmes, programas de televisão, assuntos do dia-a-dia, notícias, receitas, cartas, piadas, experiências etc.).

Assim, com base numa perspectiva sociointeracionista, para análise do caso clínico, foram enfatizados aspectos relacionados: às práticas de leitura e escrita desenvolvidas no contexto familiar; à posição de educadores envolvidos com a escolaridade de $\mathrm{A}$. acerca de seu desempenho, à postura de $\mathrm{A}$. frente às práticas de leitura e escrita, aspectos relacionados à coesão e coerência textuais, bem como, aspectos relativos ao papel do terapeuta, uma vez assumida a perspectiva teórica aqui anunciada. A análise dos resultados foi realizada a partir dos dados coletados durante o processo terapêutico ao longo de oito meses. 
Essa pesquisa foi aprovada pelo Comitê de Ética da Universidade Tuiuti do Paraná sob o protocolo número 077/2005.

\section{RESULTADOS}

Em função da queixa formulada pela escola de que o sujeito apresentava dificuldades de aprendizagem, A., com 12 anos e oito meses, foi encaminhado por um neuropediatra que solicitou avaliação do processamento auditivo central. Com base no resultado de tal exame, $A$. foi encaminhado para tratamento fonoaudiológico pelo neurologista com o seguinte laudo: "Solicito: Fonoterapia com ênfase a reabilitação do processamento auditivo. Motivo: TDA/H desatento, dislexia" (segundo laudo médico), em 18/11/2004.

A mãe de A. procurou a Clínica de Fonoaudiologia da UTP, em março de 2005, e em entrevista revelou dados referentes aos contextos familiar $\mathrm{e}$ escolar de A. que auxiliaram na análise de suas condições de leitura e escrita.

Quanto ao contexto familiar, A. convive com os pais e uma irmã mais nova. $O$ pai é mecânico e possui o ensino fundamental incompleto, a mãe é recepcionista e cursa o ensino médio. De forma geral, a família não costuma ler, mas em casa existem materiais escritos diversificados como jornais, revistas e gibis. A mãe referiu que tem o hábito de ler para a irmã de A. e que fazia o mesmo com ele quando este era pequeno, mas revela que atualmente percebe que o filho parece ler e escrever por obrigação e não apresenta interesse em tais atividades.

A mãe relatou ainda que os pais sempre notaram que o filho era "uma criança inquieta e agitada". Quanto ao contexto escolar, os pais já haviam observado que o filho apresentava dificuldades escolares em séries anteriores. Quando A. reprovou pela primeira vez a $5^{\underline{a}}$ série, referem ter avaliado o fato como algo que "faz parte".

Quando ocorreu a segunda reprovação nessa mesma série, a mãe procurou a direção da escola e, apesar de ter queixas da escola, decidiu que daria continuidade aos estudos do filho no mesmo estabelecimento por ser próximo de sua casa e possuir poucos alunos. Referiu ainda que embora soubesse que existem escolas melhores, optou por dar continuidade aos estudos de A. na mesma escola, para evitar outras que contavam com um número maior de alunos tendo em vista temer as implicações de tal fato, conforme explicitado na sua afirmação: "sabe como é, geralmente é atraído pelo grupo mau, então resolvi mantê-lo nesta escola". No final de 2004 , A. reprovou a $5^{\mathrm{a}}$. série pela terceira vez.
A principal queixa da mãe em relação à escola é que "o que ele não sabe, ninguém ensina", pois percebeu que o filho era "desligado, e a escola nunca fez nada". Segundo ela, a escola nunca a chamou para uma conversa sobre o comportamento de A., exceto ao final do ano letivo para receber a notícia de que o filho havia sido reprovado. No início de 2005, a mãe parou de trabalhar para se "dedicar ao filho, para acompanhá-lo melhor", já que percebeu que estava com dificuldades escolares. Passou, então, a freqüentar a escola para saber como era seu comportamento e quais eram seus interesses. Chegou a ser parte integrante do conselho estudantil, referindo ainda que estava ajudando na cantina da escola diariamente, para verificar como seu filho se comportava e como era tratado pelos professores.

Quanto à avaliação diretamente realizada com A., o terapeuta pode notar, nos primeiros encontros, que este se mostrava receoso e tímido. Ao ser questionado sobre os motivos que o trazia à terapia, ele disse não saber. Indagado sobre o seu desempenho escolar, mais especificamente, acerca de suas dificuldades e reprovações, $A$. inicialmente afirmou que não tinha dificuldades na escola, mas em seguida referiu dificuldades em matemática e em inglês e gostar de história e ciências. Questionado a respeito da posição dos professores acerca de seu desempenho, $A$. disse que eles nunca falaram nada sobre suas dificuldades escolares.

Ao ser questionado sobre o que gostava de ler, A. somente balançou a cabeça em sinal negativo. Com a insistência do terapeuta, revelou que não gostava de ler nada, afirmando que só lia alguma coisa se a professora pedisse. A partir das colocações e posturas assumidas por A. foi possível constatar que ele encontrava-se desmotivado em relação à escola e que procurava se esquivar de qualquer atividade proposta que envolvesse leitura e escrita.

Para maior compreensão sobre a situação escolar de A. e a posição da escola frente às suas condições de leitura e escrita, em maio de 2005, foi realizada por parte do terapeuta visita à escola. Naquela ocasião a pedagoga relatou que A. é um aluno introspectivo, tímido e que não assumia uma postura participativa nas aulas, pois além de não se colocar, não realizava as atividades propostas pelo professor. Também referiu o laudo médico que dizia que A. era portador de transtorno de déficit de atenção e hiperatividade, desatento e disléxico. Assim como o terapeuta, a pedagoga referiu que o comportamento do aluno não era de hiperatividade, pois parecia bastante tímido e, por vezes, até mesmo apático. 
Quanto às condições de leitura de A., apresentadas no início do processo terapêutico, o mesmo demonstrou dúvidas com relação à pontuação e a fluência da leitura de certas palavras, bem como dificuldades na interpretação do que lia. Quanto à escrita, foi observado que A. apresentava coesão e coerência em suas produções, embora ainda não dominasse alguns aspectos relativos à pontuação $e$ acentuação e apresentasse dúvidas quanto à ortografia, realizando omissões e trocas de letras.

$\mathrm{Na}$ avaliação da linguagem oral de A. verificouse que o mesmo não apresentava dificuldades na produção dessa modalidade de linguagem, embora falasse pouco, mostrando-se retraído e tímido.

A. freqüentou por oito meses as sessões de fonoterapia, e o trabalho prosseguiu por meio de atividades de seu interesse com o intuito de motivá-lo para as atividades com a linguagem escrita e evidenciar as diferentes funções sociais vinculadas a essa modalidade de linguagem. Durante esse processo, A. foi gradativamente assumindo uma posição mais participativa nas atividades propostas, postura também relatada pela mãe em atividades de leitura $e$ escrita vivenciadas por A. no contexto familiar.

Como parte do procedimento adotado foram desencadeadas discussões com A. acerca das dificuldades que apresentava com a linguagem escrita, como parte do processo de apropriação da mesma.

Com o intuito de encaminhar a análise deste caso, são apresentados a seguir dois textos produzidos por este sujeito, bem como as condições de produção dos mesmos. O primeiro foi produzido no início do processo terapêutico e o segundo ao final do mesmo.

Quanto à situação de produção do texto abaixo, ressalta-se que a partir de diálogos estabelecidos entre terapeuta e A., acerca de seu universo de interesse A. revelou gostar de bandas de "rock". A partir daí foram propostas leituras de artigos sobre suas bandas preferidas e que $A$. relatasse por escrito algo sobre tais bandas que julgasse interessante para compartilhar com outras pessoas.

No próximo texto, A. foi solicitado a escrever um final para uma história que havia lido.

\section{DISCUSSÃO}

No primeiro texto produzido por A. (Figura 1), é possível verificar que ele estabelece relação entre suas partes, estabelecendo coerência e progressão temática. A. iniciou sua produção com o nome da banda de rock que escolheu para dar título ao texto. Percebe-se que A. estabeleceu uma seqüência temporal na ordenação textual tentando garantir uma progressão de eventos, nos quais aparece
Nome led. zeppilin foi por causa de uma Balão que esplodio na orlanda 1950, comesarão a tocar em Bar? e gravarão o prineicede na orlanda em uma gravadora e começarão a fazer show.

Figura 1 - Produção escrita de A.

uma data, e a seguir relata os fatos que se sucederam a esta: 'começaram, gravaram o primeiro CD'. Da mesma forma, procura escrever um texto coeso, com a explicação de causalidade dos fatos 'foi por causa'. Esse tipo de fenômeno é bastante discutido pela lingüística, para explicar a possibilidade de um texto manter continuidade ${ }^{23-25}$.

A análise do texto mostra que esse sujeito demonstra condições de operar com organizadores textuais, mas é fato que esta produção apresenta incompletudes que não comprometeriam a um leitor que não tivesse um conhecimento prévio sobre o assunto, interpretar o texto. Situação, contudo, recorrentemente apresentada por crianças, adolescentes e adultos que se encontram em processo de apropriação da escrita, conforme descrito na literatura ${ }^{12}$.

Observando a seqüência textual elaborada por A., percebe-se a necessidade de um trabalho sobre seu texto escrito para que sejam explicitadas várias questões relativas à sua produção, enfim, seu texto evidencia a necessidade de um trabalho terapêutico com essa modalidade de linguagem voltado para a construção conjunta da significação ${ }^{14}$.

Procedimentos terapêuticos, tais como os utilizados nessa pesquisa, que propõem atividades e discussões para a explicitação das funções e dos usos sociais da linguagem escrita, vêm sendo analisados pela literatura fonoaudiológica como eficientes para o avanço não só de aspectos textuais da escrita como daqueles denominados como formais ${ }^{1,2,15}$.

A partir dessa perspectiva os procedimentos terapêuticos voltados à queixa, formulada pela escola e pelo neuropediatra, pautada em trocas de letras foram desenvolvidos. Manifestações ortográficas desviantes da norma, inicialmente apresentadas por A., como, por exemplo, 'comesarão' para começaram, 'esplodio' para explodiu, 'orlanda' para Holanda e omissões de letras, como em 'prineicede' para primeiro $C D$, passaram a ser trabalhadas a partir das produções textuais e, gradativamente foram diminuindo as suas ocorrências.

Com relação ao segundo texto (Figura 2), cabe esclarecer, de início, que o volume de escrita não foi adotado como critério de julgamento de capacidade 
...na hora do recreio ouvi um Barulho estranho vindo da floresta. e depois da escola eu fui lá ver.

Figura 2 - Produção escrita de A.

ou incapacidade do aprendiz, enfim o texto não foi avaliado em função de critérios extensionais, mas sim "como prática intersubjetiva que se constrói no próprio processo de enunciação" 26,27.

Durante a produção do segundo texto, o terapeuta relatou que $A$. escreveu com mais desenvoltura, conseguindo elaborar um texto com menos lacunas e, portanto, com maior autonomia de construção de sentidos. Do ponto de vista dos aspectos formais, observa-se avanço na apropriação dos mesmos, apresentando apenas um uso indevido de letra maiúscula no meio de frase, em 'barulho' que A. grafou com 'b' maiúsculo e no início da frase, após ponto final, iniciou com uma letra minúscula.

Pelo relato do caso, ao longo do processo de apropriação da linguagem escrita vivenciado por A., é possível perceber que sua postura na escola dava sinais claros de uma desmotivação com relação à escola. Tal situação, apontada pelos educadores como uma das principais causas do fracasso escolar, acabou por obscurecer os demais fatores que influenciam negativamente o processo de ensino-aprendizagem e, assim, utilizada como a justificativa das reprovações de A. por três vezes consecutivas.

Por outro lado, a família optou por, ao invés de abordar diretamente as dificuldades de A. com ele próprio e procurar ajuda para a superação das mesmas, "observar o menino de perto", enfim controlálo a partir da presença da mãe na escola. Diante dos elementos que permitem a compreensão de como o problema escolar de A. se constituiu, cabem as seguintes questões: Quais as implicações do fato da mãe referir terem optado por manter $A$. na mesma escola, mesmo tendo reprovado três vezes a mesma série, por temer que em outra escola ele se envolvesse com a "turma do mal"? Quais as implicações do fato da família ter procurada ajuda apenas após a terceira reprovação de A.?

Cabe ressaltar, que os sentidos e a trajetória percorrida por A. acerca da linguagem escrita são construções diretamente condicionadas pelas posições e visões assumidas pelos adultos que fazem parte de sua vida ${ }^{28}$. Por isso, o fonoaudiólogo precisa estar atento à relação que o aprendiz estabelece com a escrita a partir dos discursos e das práticas que o circundam nos contextos clínico, familiar e escolar ${ }^{27,28}$.

Durante o processo terapêutico fonoaudiológico os procedimentos objetivavam, prioritariamente, que A. compreendesse o papel do terapeuta a partir da perspectiva assumida, ou seja, o papel que o terapeuta assumiria nesse processo: - reconhecer A. como capaz de se apropriar da escrita, ser co-autor dos textos escritos em terapia a partir de vivências de leituras e escritas significativas e prazeirosas, participar da construção textual a partir da co-autoria de textos cujos sentidos poderiam ser compartilhados com outros leitores, participar da apropriação dos aspectos formais da escrita, explicitando as hipóteses formuladas por A. que resultassem manifestações desviantes da norma e oferecendo elementos que pudessem a A. avançar na apropriação de tais aspectos ${ }^{21}$.

A partir da análise aqui realizada buscou-se enfatizar que a apropriação da escrita implica a constituição de sentidos lingüísticos, a qual depende da interação estabelecida com o outro por meio de atividades significativas com e sobre a linguagem 1,3,19-21.

\section{CONCLUSÃO}

Considerando o objetivo desse estudo, discutir a apropriação da escrita na clínica de linguagem, tendo em vista o processo interativo estabelecido entre o aprendiz e o fonoaudiólogo, é possível concluir que tal apropriação se dá na relação intersubjetiva, na qual estão vinculados, dentre outros pares, o sujeito e o terapeuta.

Foi a partir dessa intersubjetividade, pautada em uma visão discursiva da linguagem que $A$. pode ser percebido como capaz de fazer uso significativo da escrita e, assim, apresentar mudanças na relação estabelecida com as práticas de leitura e escrita, adquirindo, ao longo do processo, maior autonomia em relação aos diferentes aspectos que constituem essa modalidade de linguagem. 


\section{ABSTRACT}

Purpose: supposing that the linguistic activity constitute the subject, this work aims to discuss the written appropriation process, in a language clinic, from the relation that the apprentice establish with the speech language therapist. Methods: one clinic case of a subject to whom reading and writing were distant from the conventional orthographic rules was analyzed. After speech language therapy evaluation, the written language productions seem to be distant from the orthographic conventions. Results: language therapy was efficient for the appropriation of the written language, as during the treatment the complaints were surpassed. Conclusion: through the construction of the written language between the speech language therapist and the subject of this research, the first one could be noted as someone who is capable to use written language meaningfully.

KEYWORDS: Language; Handwriting; Speech Therapy

\section{REFERÊNCIAS}

1. Massi GAA. A escrita de um aluno: uma análise lingüístico textual. Pró-Fono. 2001; 13(2):190-8.

2. Dauden AT, Mori CC. Linguagem escrita: tendências e reflexões sobre o trabalho fonoaudiológico. São Paulo: Pancast; 2004.

3. Berberian AP, De Angelis CCM, Massi GAA. Violência simbólica nas práticas de letramento. In: Berberian AP, De Angelis CCM, Massi GAA, organizador. Letramento: referênciais em saúde e educação. São Paulo: Plexus; 2006. p. 15-32.

4. Alvarez AMMA, Caetano AL, Roman R. Diagnóstico e reabilitação da dislexia: uma visão neuropsicológica. Rev CEFAC. 1999; 1(2):96-106.

5. Jakubovicz R. A percepção visual e a possível correlação com a aprendizagem da leitura e da escrita. Rev Soc Bras Fonoaudiol. 1998; 2(4):6-11.

6. Lewis BA, Shriberg LD, Freebairn LA, Hansen AJ, Stein CM, Taylor HG, et al. The genetic bases of speech sound disorders: evidence from spoken and written language. J Speech Lang Hear Res. 2006; 49(6):1294-312.

7. Catts HW, Adlof SM, Hogan TP, Weismer SE. Are specific language impairment and dyslexia distinct disorders? J Speech Lang Hear Res. 2005; 48(6):1378-96.

8. Fey ME, Catts HW, Proctor-Williams K, Tomblin $\mathrm{JB}$, Zhang $\mathrm{X}$. Oral and written story composition skills of children with language impairment. J Speech Lang Hear Res. 2004; 47(6):1301-18.

9. Wise JC, Sevcik RA, Morris RD, Lovett MW, Wolf $M$. The relationship among receptive and expressive vocabulary, listening comprehension, pre-reading skills, word identification skills, and reading comprehension by children with reading disabilities. J Speech Lang Hear Res. 2007; 50(4):1093-109.
10. Andrade L. Ouvir e escutar na constituição da clínica de linguagem. [doutorado]. São Paulo (SP): Pontifícia Universidade Católica de São Paulo; 2003.

11. Wolter JA, DiLollo A, Apel K. A narrative therapy approach to counseling: a model for working with adolescents and adults with language-literacy deficits. Lang Speech Hear Serv Sch. 2006; 37(3):168-77.

12. Guarinello AC, Berberian AP, Santana AP, Massi GAA, Rivabem K, Jacob LCB, et al. Dificuldades de aprendizagem da escrita: uma análise de acompanhamentos clínicos dessa modalidade de linguagem. Rev Letras. 2006, 70:247-66.

13. Felippe $A C N$, Colafêmina JF. Avaliação do processamento auditivo e o desempenho em tarefas de leitura-escrita. Pró-Fono. 2002; 14(2):225-34.

14. Perrotta C, Massini L, Märtz MLW. O trabaIho terapêutico fonoaudiológico com a linguagem escrita: considerações sobre a visitação a gêneros discursivos. Dist Comun. 2004; 16(2):181-94.

15. Guarinello AC, Pan MAGS. As contribuições da lingüística textual para avaliação da linguagem na infância. Pró-Fono. 2001; 13(2):181-9.

16. Massi GAA. Reflexões sobre o processo de aquisição da escrita e a dislexia. Rev Letras. 2005; 65:153-72.

17. Guarinello AC. O papel do outro na produção escrita de sujeitos surdos. Dist Comun. 2005; 17(2):245-54.

18. Santana AP. A linguagem na clínica fonoaudiológica: implicações de uma abordagem discursiva. Dist Comun. 2001; 13(1):161-74.

19. Perrotta C. Breve estudo de caso: uma abordagem da escrita na terapia fonoaudiológica. Dist Comun. 2002; 14(1):91-102. 
20. Perrotta C. O trabalho terapêutico fonoaudiológico com a linguagem escrita: considerações sobre a visitação a gêneros discursivos. Dist Comun. 2004; 16(2):181-93.

21. Guarinello AC, Gregolin RM. As produções escritas de sujeitos surdos. Rev. Letras. 2005; 65:135-51.

22. Franchi C. Criatividade e gramática. Trab Lingüíst Apl. 1987; 16:5-45.

23. Bronckart JP. Atividade de linguagem, textos e discursos: por um interacionismo sócio-discursivo. São Paulo: EDUC; 1999.

24. Marcuschi LA. Anáfora indireta: o barco textual e suas âncoras. Rev Letras. 2001; 56:217-58.
25. Miilher LP, Ávila CRB. Linguistic and narrative variables in oral and written language disorder. PróFono. 2006; 18(2):177-88.

26. Massi G, Gregolin R. Reflexões sobre o processo da aquisição da escrita e a dislexia. Rev Letras. 2005; 65:153-71.

27. Nippold MA, Duthie JK, Larsen J. Literacy as a leisure activity: free-time preferences of older children and young adolescents. Lang Speech Hear Serv Sch. 2005; 36(2):93-102.

28. Moysés MAA, Collares CAL. A história não contada dos distúrbios de aprendizagem. Cad Cedes. 1992; 28:23-50.

RECEBIDO EM: 29/03/2007

ACEITO EM: 03/12/2007

Endereço para correspondência:

Rua Alexandre Eduardo Klat, 66/02

Curitiba - PR

CEP: 82130-120

Tel: (41)33317850

E-mail: ana.guarinello@utp.br 